\title{
THE INFLUENCE OF PRECEDENCE TECHNIQUES APPLICATION TO THE PAVEMENT NETWORK FUNCTION
}

\author{
Fathy M. Mándeel \\ Faculty of Engineering, \\ Zagazig University, EGYPT
}

\author{
Essam A. Sharaf \\ Faculty of Engineering, \\ Cairo University, EGYPT
}

\begin{abstract}
Precedence setting techniques as used in the Pavement Maintenance Management Systems (PMMS) cover a wide spectrum of methods and approaches ranging from simple precedence lists based on engineering judgment to complex network optimization models. In this paper, three precedence setting techniques are presented along with the results of their applications using data collected from the Egyptian road network. The first technique is a simple ranking one in which four ranking measures was used in the analysis: (i) lowest life cycle cost; (ii) worst condition first; (iii) highest traffic and (iv) highest benefit/cost ratio. The second technique is a combined ranking technique based on relative weights assigned to the above mentioned four ranking measures. Finally, the third technique is a linear programming optimization model, which considers both time (current and future) and space (entire network). A comparison between the three techniques, in terms of network condition over time and in terms of budget deficit over time, is presented in the paper. The results indicated a considerable difference in future network performance under the three techniques, with the optimization technique producing the best results.
\end{abstract}

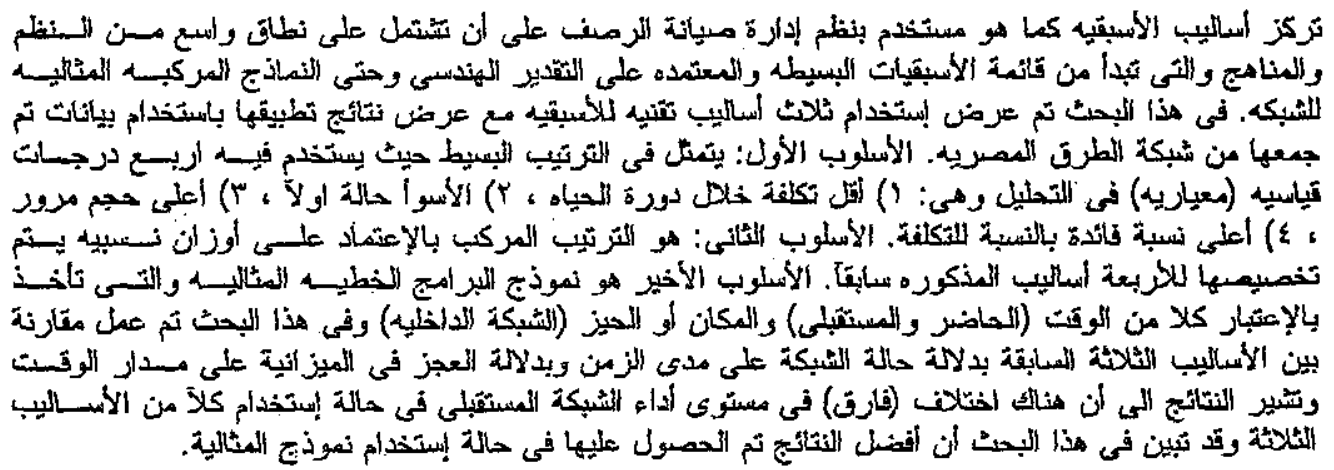

Keywords: Precedence techniques, pavement maintenance, prioritization, optimization, pavement condition

\section{INTRODUCTION}

The process of setting maintenance priorities is of utmost importance to the entire PMMS process. This may referred to the fact that the precedence setting is the step after which a final decision has to be made on the maintenance program to be executed. In addition, and even more important, the quality of the precedence setting is directly influencing the effectiveness of utilizing available resources which, in most cases, is a prime goal of a decision maker. So, the massive efforts typically allocated to the data collection and needs assessment phases could very easily be wasted if the appropriate precedence schemes were not applied. The degree of complexity, or comprehensives, of a precedence setting scheme is generally a function of the level of considering the time (current or future) and space (section by section or the entire network) dimensions when dealing with the network condition (Lyton \& Shahin \& Way 1985).

The selection of maintenance policies for different road sections is influenced by a number of factors including pavement condition, traffic volume, environmental effects, desired performance standards, and budgetary constraints. Since maintenance actions affect the scheduling of work and allocation of resources, proper selection of such actions (priorities) is crucial to the most efficient use of limited resources to demonstrate specifically how funds are allocated and; what benefits would be 
gained with additional funds and what the effect of delaying the maintenance of a portion of the on the long range (Kuikarni, 1980).

All ranking and optimization methods used in setting maintenance priorities require the collection of data on the current condition of the network roads and make a complete time.cost stream analysis for each link (Darter 85). A decision tree or intervention logic is used to identify the appropirate maintenance alternatives for each road section in the network based upen its current condition compared to certain threshold criteria. These threshold criteria or minimum standards define a rinimum acceptable pavement condition indicating how far conditions should be allowed to detericrate before active considerations are required. If the pavement on a particular road is not currently in need for rehabilitation or maintenance, deterioration models are used to predict the time in future when a maintenance action is needed. Then costs of each feasible alternative for each road section are estimated to determine which of these is more cost effective or will provide the maximum benefit (Lyton, 1985).

The purpose of this paper is to demonstrate the use of three different precedense setting techniques: The first technique is a simple rariking one. Four ranking measures were used in the analysis: (i) lowest life cycle cost; (ii) worst condition first; (iii) highest benefits and (iv) highest benefit/cost ratio. The second technique, is a combined ranking technique based on relative weights assigned to the above mentioned four ranking measures. Finally, the third technique is a linear programming optimization model, which considers both time (current and future) and space (entire network).

The contents of this paper are divided to three main parts. In the first part, a brief review of the items associated with time-cost strearn analysis will be presented. The second part contains brief description of the ranking and optimization methods as used in this study. Finally, in the third part, a comparison between the results of applying different ranking and optimization precedence setting techniques will be discussed.

\section{TIME-COST STREAM ELEMENTS}

In this procedure, each link (road section) that received (or planed to receive) a maintenance altemative is represented by a set of economic indicators. These indicators are based on establishing the time-cost stream for each alternative (link). The basic components of the time-cost stream analysis are:

1. Initial cost.

2. Aunual maintenance costs,
3. Benefits resulting from the application of the alternative.

The following are definitions of the basic terms used in the procedure to calculate the above cost and benefit components. Pavement condition: visual inspection using the Pavement Condition Index (PCI) has been used in this procedure (NTI 90). PCI is a well known procedure and was originally deveioped by the U.S. Army corps of engineers (Shahin 81). It depends on a detailed inspection of pavement and covers up to 19 different distress types; each of them is defined by its type, severity level and extent (density). The final rating of the pavement condition is based on the calculation of the PCI value which ranges from 0 to 100 with 100 being excellent. The PCI data and rating are used to determine appropriate maintenance activity for a road section, and consequently the associated initial and annual maintenance costs. On the other hand, another pavement condition indicator has been used to estimate user costs/benefits. This indictor is the Interrational Roughness Index (IRI), which takes the values 0 to 20 with 0 being excellent. It represents the degree of unevenness of pavement surface which is highly correlated to Vehicle Operation Costs (VOC) (Ashok 86).

PCI Ranges: because maintenance decisions are discrete in nature, pavement condition, represented by $\mathrm{PCl}$ values, is also divided into discrete ranges as follows: $(80-100),(60-80),(40-60),(20-40)$ and $(0-$ 20). Density Matrix: it summarizes the average density values ( $\%$ of section area indicating specific distress type) for each PCI range by distress type and severity level combinations.

Maintenance Types (activities): six maintenance types were considered in this procedure: (i) do nothing; (ii) routine (annual or recurrent) maintenance; (iii) surface dressing; (iv) thin (functional) overlay; (v) thick (structural) overlay and (vi) reconstruction.

Surface Preparation Policy Matrix: it contains the necessary surface preparation actions for different distress-severity level combinations. These actions are converted to the corresponding surface preparation costs. Routine (annual) Maintenance Policy Matrix: it contains the necessary routine maintenance actions for different distress-severity level combinations. These actions are converted to the cortesponding routine maintenance costs.

Performance Models: they are the relations that describe the rate of change in pavement condition over time, under certain level of use (traffic) and subjected to specific environmental factors. These models are used to estimate the future condition of pavemert sections. This way future maintenance types and costs can be estimated allowing for 
establishing the time-cost streams over the analysis period. The general model used in this study is given in Equation 1 .

$$
\text { PCI }=100-b *(\text { age })^{m}
$$

where,

$$
\begin{aligned}
& \text { PCI }=\text { Pavement Condition Index } \\
& \mathbf{b}=\text { slope coefficient } \\
& \text { age }=\text { pavement age at a specific point of time } \\
& \mathrm{m}=\text { value that controls the degree of curvature } \\
& \text { of the performance curve. }
\end{aligned}
$$

The above terms were extensively used to establish the time-cost.streams associated with each road section (maintenance alternative), namely initial cost, annual maintenance costs and benefits as summarized below. Initial cost (fixed part): which has no relation to the condition of the existing pavement, can be estimated from the most current similar contracts. Initial cost (variable part): it is also called surface preparation cost and is directly related to the condition of existing pavement at the time of activity application. It is calculated using Equation 2, taking into consideration the existing condition (PCI range) of the pavement.

$$
(\mathrm{SP})_{\mathbf{k}}=(\mathbf{D i j})_{\mathbf{k}} *(\mathbf{C i j})_{\mathbf{s p}}
$$

where,

$(\mathrm{SP})_{\mathrm{k}}=$ Surface preparation cost at the $\mathrm{k}^{\text {th }} \mathrm{PCI}$ range.

$(D i j)_{k}=$ Average density of the ith distress type with the th severity level combination at the kth $\mathrm{PCl}$ range

$(\mathrm{Cij})_{\mathrm{sp}}=$ Unit cost of the required surface preparation work for the th severity level of the ith distress type (from the surface preparation policy matrix)

Annual (recurrent) maintenance cost: it is directly related to the condition of the pavement for each year within the 'service life of an alternative: It is estimated using Equation 3 taking into consideration the $\mathrm{PCI}$ range during each year of the alternative service life:

$$
(\mathrm{RM})_{\mathrm{k}}=(\mathrm{Dij})_{\mathrm{k}} *(\mathrm{Cij}) \mathbf{r m}
$$

where,

$(\mathrm{RM})_{\mathrm{k}}=$ Annual maintenance cost at the $\mathrm{k}^{\text {th }} \mathrm{PCI}$ range.

$\left(D_{i j}\right)_{k}=$ Average density of the ith distress type with the $\mathrm{jth}$ severity level combination at the $\mathrm{k}^{\text {th }}$ PCl. range

$\left(D_{i j}\right)_{k}=$ Unit cost of the required recurrent maintenance work for the $\mathrm{j}^{\text {'h }} \mathrm{h}$ severity level of the ith distress type (from the recurrent maintenance policy matrix)
Savings (benefits): savings are the difference between the VOC value in a specific year with specific IRI value and the VOC value at the terminal IRI value. The calculation is done for each year within the service life of an alternative. The IRI values are estimated using the simple statistical relation shown in Equation 4 (Sharaf 89 and AbdAllah 90):

$$
\text { IRI }=\mathbf{0 . 1 5}(\mathbf{1 0 0}-\mathbf{P C I})
$$

The VOC values are then calculated using the general model developed by the World Bank (Equation 5)

(VOC) $=e^{\left(\mathrm{a}+\mathrm{b}^{*} \mathrm{IR}\right)}$

Where,

VOC $=$ estimated vehicle operation cost $($ Pound 1 000 veh-km)

$A^{\prime} \& b=$ constants, their values depend on vehicle type as follows:

$\begin{array}{lcc}\text { Vehicle Type } & \underline{\mathbf{a}} & \underline{\mathbf{b}} \\ \text { passenger car } & 5.634 & 0.06814 \\ \text { small trucks } & 6.337 & 0.06516 \\ \text { medium trucks } & 6.165 & 0.06766 \\ \text { articulated trucks } 6.889 & 0.05116 \\ \text { International Roughens Index }\end{array}$

IRI = International Roughens Index

\section{PRECEDENCE SETTING TECHNIQUES}

In this study, three levels of precedence setting techniques were used: (i) simple ranking; (ii) combined index ranking and (iii) optimization. A brief description of each of these techniques as used in this study is presented in the following sections.

\subsection{Simple Ranking}

\subsubsection{Lowest Life Cycle Cost Precedence Measure}

The road sections are carefully cost - analyzed and a time - cost stream is projected for the different maintenance alternatives. Then, an economic method is applied for each road ( present worth, equivalent uniform annual cost, ..etc.) to accumulate the life cost to a certain time. The Present. Worth (PW) method issued to accumulate the total life - cost to a present value and then a high precedence is given to the lowest present worth. The network road sections are ranked in an increasing order, from the lowest to the highest PW: Thereafter, the available budget is charged so, low precedence roads are dropped until the available budget is met.

\subsubsection{The worst Condition First Precedence Measure}

This method is based on maintaining the network road sections of the worst condition first leaving other links of relatively good condition deteriorate to later maintenance program. The worst - first ranking method is applied after a complete evaluation of the 
network links. The suitable maintenance alternatives are applied for each link and the cost of each treatment is charged within a complete life cycle cost analysis process. Subsequently, the total life cycle costs are accumulated at present using the "PW" method. The available budget is charged, so that low precedence road sections are dropped until the available budget is met to all the treated road sections with the worst condition ranked firstly.

\subsubsection{Highest Traffic Precedence Measure}

It is similar to the previous merhod except that road sections with higher traffic volumes are ranked firstly.

\subsubsection{Highest Benefit I Cost Precedence Measure}

The benefits, as discussed earlier, are those resulting from savings in vehicle operating costs. The VOC savings resulting from the application of an alternative equals to the difference in VOC value when not applying the alternative and that when applying that altemative. This way, alternatives with higher performance are expected to produce higher VOC savings during their service lives. Benefit/Cost $(B / C)$ ranking is a method based on the benefit $I$ cost ratio result from in - depth analysis of costs and benefits for the network road sections. The road sections are ranked in a descending precedence order, from the highest $B / C$ ratio to the lowest one.

\subsection{Combined Index Ranking Technique}

The Combined Inclex Ranking (CIR) is a technique developed for setting pavement maintenance priorities based upon assigned, user defined, relative weights for different measures. In this study, relative weights are assigned to each of the previous four measures. Hence, a Combined Index Score 'CIS' is used as a summary score and is used for setting priorities of road sections. Highest priorities are given to the highest 'CIS'. The combined index score is expressed as shown in Equation 6.

$$
\mathbf{C I S i}=\sum_{i=1}^{n} e_{i j} * \mathbf{W} \mathbf{j}
$$

Where,

$$
\begin{aligned}
& \text { CIS }_{i}=\text { summary score for } i^{\text {th }} \text { road section. } \\
& \mathrm{e}_{\mathrm{ij}}=\text { rating of } \mathrm{i}^{\text {th }} \text { road section with respect to the } \\
& \mathrm{j}^{\text {th }} \text { measure. } \\
& \mathrm{Wj}=\text { weight of } j^{\text {th }} \text { measure, user defined. } \\
& \mathrm{N}=\text { number of measures }(\mathrm{n}=4)
\end{aligned}
$$

\subsection{Optimization Technique}

The basic requirement of the optimization technique is that it considers both time (current and future) and space (entire network). To accomplish this, road sections are categorized into different condition states based on factors such as pavement condition and traffic levels. The proportion of the retwork in each of the condition states at different time periods defines the performance of the network over time. The objectives of the optimization technique are: maximization of benefirs (performance standards), minimization of costs and minimization of the deficient portion of the network. The required components to accomplish these objectives are; selection of a functional criteria, performance variables, road categories and condition states, specification of maintenance alternatives and then, development of the mathematical model. There are three components of the mathematical representation of the optimization technique: (i) decision variables; (ii) objective function; and (iii) the constraints

(i) Decision Variables: whose values are to be determined and defined by, $W_{i, k}^{n}$ the proportion of road sections in condition state ' $i$ ' at year ' $n$ ' to which maintenance action ' $k$ ' will be applied within the analysis period ' $\mathrm{T}$ '.

(ii) Objective Function: which is to be maximized (benefits) or minimized (cost and the deficient portion of the network). These objectives are represented mathematically as shown in Equations 7 through 9.

Maximize $\sum_{\text {states,k }}^{\text {acceptable }} \quad W_{i, k}^{T} \geq m$ (maximize the benefits)

\{maximize the proportion $11 \mathrm{~m} 11$ of the network allowed to be in acceptable condition?

Minimize $\sum W_{i, k}^{T} * C(i, k)$ (minimize the total cost)

fminimize the total cost " $\mathrm{C}$ " for all condition states ' $i$ ' and maintenance action ' $k$ ')

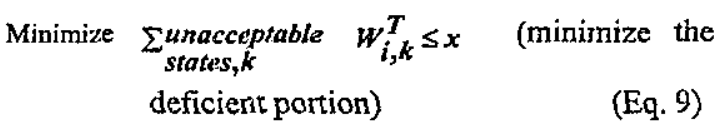

\{minimize the proportion " $\mathrm{x}$ " of the network allowed to be in unacceptable condition)

(iii) Constraints: to be satisfied by the decision variables (Equations 10-14)

The proportions $\mathrm{Wj},:$ must be non - negative,

$$
w_{i, k}^{T} \geq 0 \text { for all } \mathrm{I} \& \mathrm{~K}
$$

The sum of proportions of roads with different condition states ' $i$ ' and maintenance action ' $k$ ' of the network for each year $=1$

$$
\sum_{i, k} W_{i, k}^{T}=1
$$


The proportion of road sections in a given condition state " $\mathrm{j}$ " is equal to the proportion of road sections in the condition state " $\mathrm{i}$ " multiplied by the proportion of road sections thät move from state "i" to state "j" in one time period if a maintenance action " $k$ " is applied to the road section

$$
\sum_{k} W_{j, k}^{T}=\sum_{i, k} W_{i, k}^{T} * P_{i, j}\left(a_{k}\right)
$$

$\mathbf{P}_{\mathrm{l}, \mathrm{J}}\left(\mathbf{a}_{\mathbf{k}}\right)=$ proportion of roads that move from condition states " $\mathrm{i}$ " to " $\mathrm{j}$ " as a result of a maintenance action " $k$ "

If $\mathrm{k}^{\text {th }}$ maintenance action is unfeasible for $\mathrm{i}^{\text {th }}$ condition state, then

$W_{i, k}^{T}=0$

The cost should match that of the optimum policy. Therefore:

$$
\sum_{i, k}^{T} \times C(i, k) \leq C^{*} \times(1+b)
$$

$C^{*}=$ the cost of the optimum policy, allowable budget, determined previously.

b = specified tolerances

\section{COMPARISON BETWEEN THE THREE TECHNIQUES}

The results of applying the three precedence setting techniques, described in the previous section, on Egypt road network will be presented in this section. The purpose of this section is to evaluate the efficiency of these techniques and discuss the possible reasons behind the differences in the results when applying them. Before introducing the results of applying the three techniques, the following remarks need to be mentioned:

1. An analysis period of 15 years was assumed with 5 years interval at which a maintenance action should be applied.

2. The results of the 1990 Egypt network condition survey for 265 link with $9846 \mathrm{~km}$ length was used in all techniques for identifying the maintenance needs.

3. An interest and inflation rates of $16,12 \%$, respectively were used.

4. A limited budget value of 1,600 million L.E (during the analysis period) was used.

5. In the combined index technique, a standard relative weights of $8,5,3$,and 2 were considered for the four measures.

6. To evaluate the efficiency of the techniques, three main indicators were considered. First, the deficit budget, which indicates the difference between the budget required to upgrade the network and the available budget. Second, the deficient portion of the network, which represents the general condition of the network in terms of the percent from total network that need of major maintenance (rehabilitation or overlay) and left without maintenance. The third indicator is the benefits that result from application of different maintenance alternatives. Generally the higher the value of the deficit budget or deficient portion indicators the less efficient is the maintenance program. On the other side, the higher, the value of the benefits indicates an efficient maintenance program.

Table 1 shows the resulting deficit budget, deficient portion and benefit values under the simple ranking measures and optimization techniqque, respectively. It is obvious that the optimization technique produced the best results for the three indicators. Optimization technique produced the lowest deficit budget, the lowest deficient portion (excluding lowest cost ranking measure) and the highest benefits (excluding highest $B / C$ ratio ranking measure). It is noticed also that lowest cost and highest $B / C$ ratio simple ranking measures produced the lowest deficient portion and highest $B / C$ ratio, respectively. This is because, the lowest cost ranking measure tends to select roads with lowest cost (good condition) only, and $B / C$ ratio ranking measure selects roads with highest $B / C$ ratio ignoring other objectives.

The superiority of the optimization technique can be explained as follows:

i. The ranking method identifies and quantifies links to be treated by one of the allowable treatments and ranks the various treatments to set them in a precedence list in order of importance such that primary links will be treated, by the limited budget, while the rest of defected links will be deferred to next years, even that they will be more deteriorated.

ii. Thus, the ranking methodology does not consider the effect of delay of maintaining candidate links. In other words, variations in costs and benefits associated with timing of the investment are not considered. Ranking, also, is not adequate as it does not spread available funds as far as possible on the candidate projects.

This means that, if primary projects have high capital costs, then they will consume all the budget available leaving the rest of projects for more deterioration. The optimization technique, on the other hand, considers all possible combinations of network links when selecting the optimum set of priorities from the network as a whole in order to maximize the efficiency of maintaining network roads subject to the limited budget. 


\section{SUMMARY AND CONCLUSIONS}

Three precedence setting techriques were presented in this paper. The first technique is a simple ranking one based on four measures; (i) lowest life cycle cost; (ii) worst condition first; (iii) highest traffic and (iv) highest benefit/cost ratio. The second technique, is a combined ranking technique based on relative weights assigned to the above mentioned four ranking measures and the third technique is a linear programrning optimization model, which considers both time (current and future) and space (entire network). An application of these techniques was done using a comprehensive data survey on Egypt road network and a computerized decision support system program. The results indicated the superiority of the optimization technique in terms of improved budget deficit, reducing the deficient portion of the network and emend the future network performance (in terms of higher benefits). Although the complexity of the optimization technique, it represents a suitable means for setting pavement maintenance priorities for effective utilization of the limited funds.

\section{REFERENCES}

[1] Abd-Allah AM. 1990. Analysis of Flexible Pavement Roughness in Egypt. M.Sc. Thesis, Faculty of Engineering, Zagazig University, Egypt.

[2] Ashok Dhareshwar and Rodrigo ArchonoCallao, 1986. Vehicle Operating Cost Prediction. Transportation Department, The World Bank.

[3] Darter,M.L., Smith, R.E., and Shahin, M.Y., 1985. Use of life Cycle Cost Analysis as the Basis for Determining the Cost-Effectiveness of Maintenance and Rehabilitation Treatments for Developing: A Nelwork Assignment Procedure, North American Pavement management Conference, Vo1.2, Toronto, Ontario, Canada.
[4] E1 Hawary, M., Osman, A, Gadallah, A and Abdel Naser, K.,Consultants, ARE, Transport and Road Research labor -atory, UK, 1987. Road Maintenance Project. Ministry of Transport, Egypt.

[5] lyton, R.L., 1985. Moderate report, from Ranking to optimization. Proceeding of North American Pavement Management Conference. $\mathrm{Vo} / .3$, Toronto.

[6] National Transportation Institute, Ministry of Transportation, Arab Republic of Egypt, 1990 . Study on the Effect of increase in Vehicles Axle loads on the Egyptian Roads, National Transport Institute, Cairo, Egypt.

[7] R. Kulkami , K.Golabi , F. Finn and E. Alviti with Consulting Assistance from L. Nazareth 1980. Development of a Network Optimization System. Prepared for Arizona Department of Transportation, Final Report.

[8] Shahin, M.Y., and Khon , S.D., 1981. Pavement Maintenance Management for Roads and Parking Lots. U.S. Corps of Engineers, Technical Report, No. CERL - TR - M - 294.

[9] Shahin. M.Y.,Khon, S.D., Lyton. R.L. and Mcfarland, W.F., 1985. Pavement M\&R Budget Optimization Using the Incremental BenefitCost Technique. Proceeding of North American Pavement Management Conference. Vol. 2, Toronto, Canada.

[10] Sharaf, E. A..and Hanno, D. F. 1989. An Analysis of the Effect of Pavement Condition on Vehicle Operating Costs. Proceedings of the AIAzhar Engineering First Conference, Cairo, Egypt.

[11] Way, G.B., 1985. Network Optimization System for Arizona. Proceeding of North American Pavement Management Conference. Vol, 2, Toronto, Canada. 
F. Mandeel, E. Sharaf, "The Influence Of Precedence Techniques Application to the Pavement Network Function"

Lowest Cost Whorst Condition Whighest traffic 1 Highest Benefit Doptimum

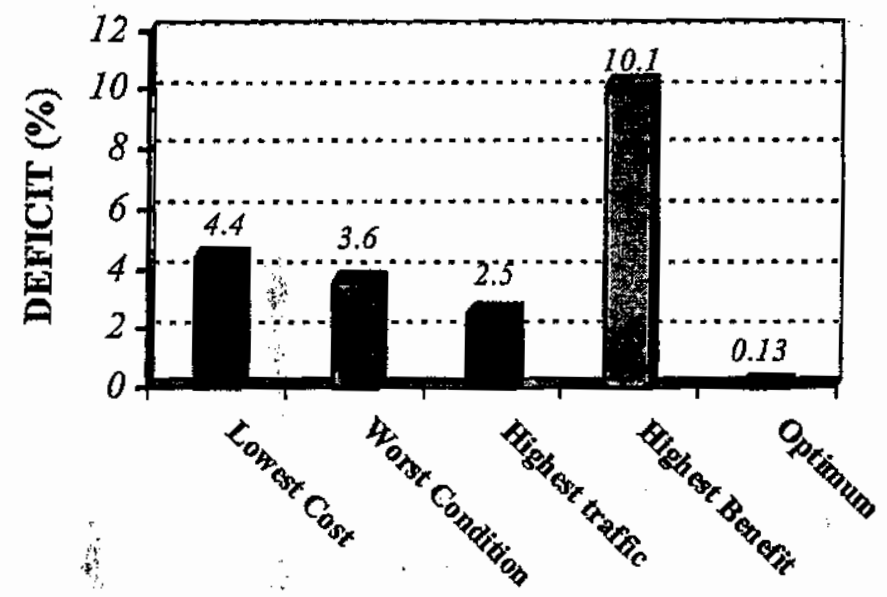

Precedence Techniques

Figure (1) The effect of different precedence techniques to the deficit portion of the network

Lowest Cost Worst Condition Highest traffic 1 Highest Benefit 1 Optimum

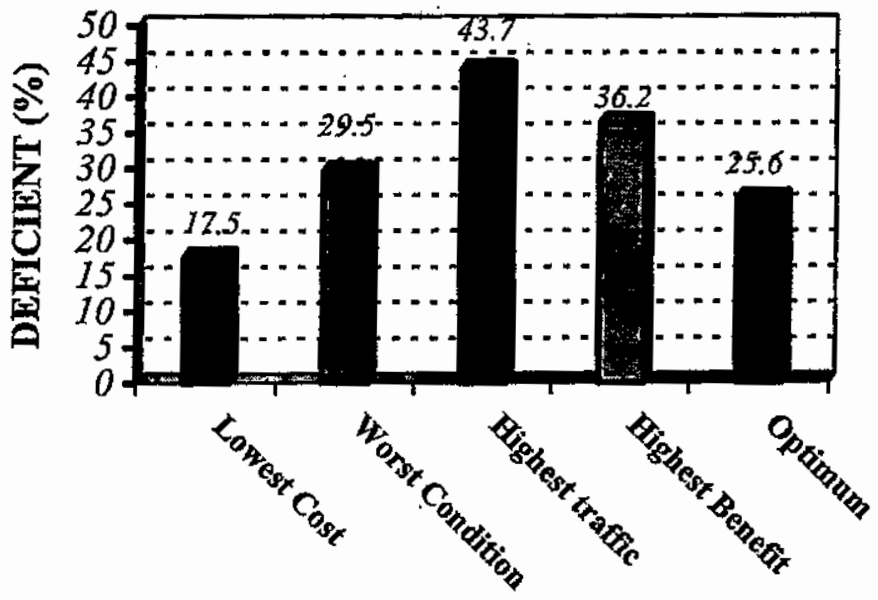

Precedence Techniques

Figure (2) The effect of different precedence techniques to the deficient portion of the network 


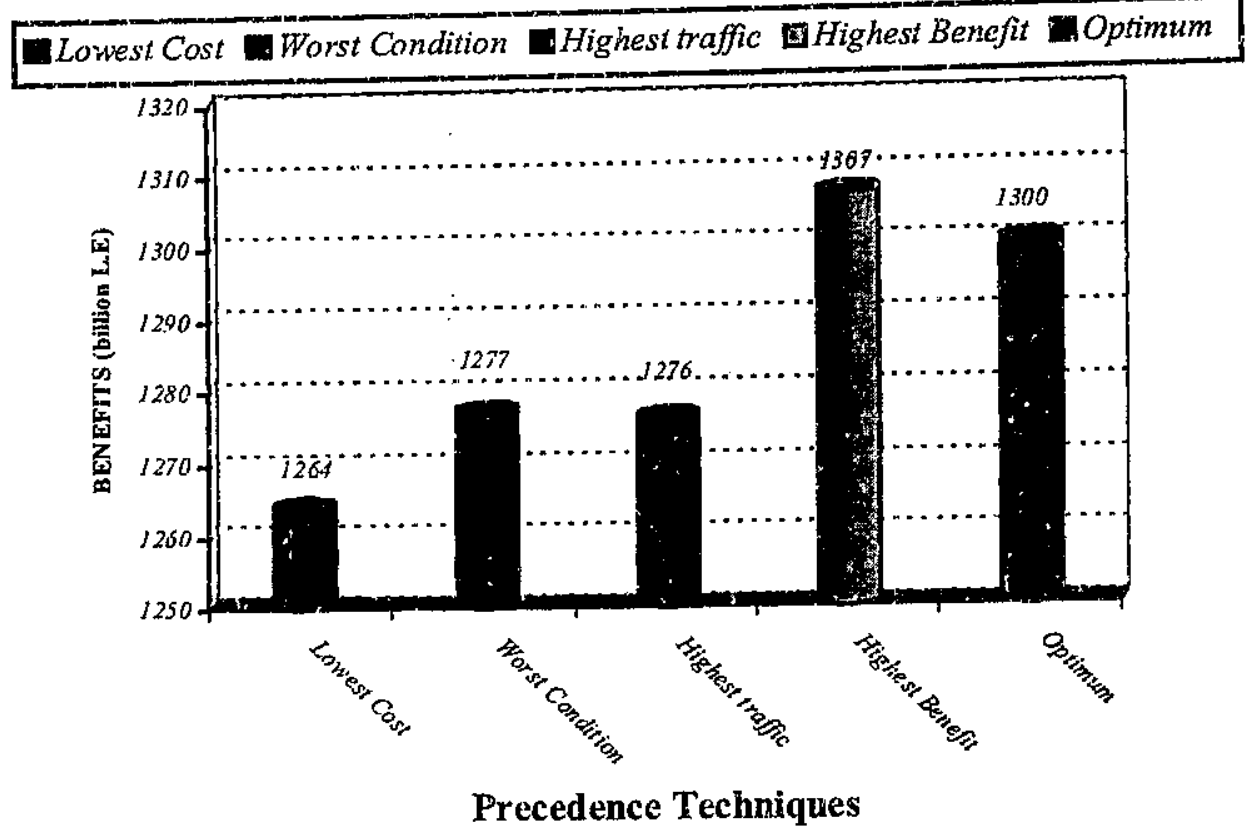

Figure (3) The benefits result from the application of each precedence technique 